\title{
Integrated Communication - \\ A Phenomenon in a Nascent State
}

\author{
Andžela Armonienè \\ University of Vilnius, Lithuania
}

andzela.armoniene@kt.vu.It

\begin{abstract}
A lot of research questions are surrounding the implementation of the concept of integrated communication and possible solution may be a process of evolutionary developed integration as well as a new understanding of strategic planning directed by an outside-in view. The movement toward outside-in development seems to be one of the greatest transformations and the mostly difficult to overcome obstacle. This process has started together with the boom of information and communication technology and has still been in a nascent state, which is related to tremendous energy condensation and the greatest potency in a new age. However, difficulties of measurement are not helpful for building an original wholeness of theoretical and methodological premises of integrated communication. Thus, the article is aimed to introduce some initial findings about the cultivation of the "tulip rose" (Rosengren, 1989, 28) in this research field of reinvented and redesigned communication.
\end{abstract}

Key words: integrated communication, outside-in view, nascent state.

...Corporate communication as we have known it in the $20^{\text {th }}$ century is not likely to survive the first hectic years of the new century (Nemec, 1999).

\section{Introduction}

Without any doubt, it is important to originate innovative and research based approaches and also fresh thinking in areas of communication management. Simply speaking, the time for "redesigning organisations information and learning systems and shaping the communication philosophy" (Gayeski and Woodward, 1996) has come. Being in the know about problems of measurability of the emerging concept of integration and having results of George $S$. Low's (2000) research and other only few empirical studies of integrated marketing communications (IMC) (Duncan and Everet, 1993; Schultz and Kitchen, 1997; Kitchen and Schultz, 1999; Gould, Lerman and Grein, 1999), it is purposeful to concentrate on making qualitative

Material published as part of this proceedings, either on-line or in print, is copyrighted by the author with permission granted to the publisher of Informing Science for this printing. Permission to make digital or paper copy of part or all of these works for personal or classroom use is granted without fee provided that the copies are not made or distributed for profit or commercial advantage AND that copies 1) bear this notice in full and 2) give the full citation on the first page. It is permissible to abstract these works so long as credit is given. To copy in all other cases or to republish or to post on a server or to redistribute to lists requires specific permission from the author. and also quantitative research (Yin, 1994) of integrated communication (IC) as improved level of IMC and to overcome narrow specialisation. In that case, introduction of existing differences between IMC and IC is the main starting point of this article. Chosen presumption, which hypothetically leads to the understanding of possible universality of the emerging concept, is:

Integrated communication may be implemented in governmental institutions as the most effective communication management project. The issue of the creative borrowing of experience and many of techniques of integrated communication realisation from the advanced corporations might be not very problematic (Armonienè, 1999).

An essential thesis of this study is related to integrated communication, which may be harmoniously implemented in every kind of organisation. Rather like idea was firstly mentioned by Schultz, Tannenbaum and Lauterborn in the widespread text about IMC in 1992, republished in 1994.

Hence, this article outlines the movement from theoretical questions toward methodological issues and research design, which incorporates investigations of values, according to qualitative research (Marshall and Rossman, 1999; Gorman and Clayton, 1997) traditions, and also quantitative study. The second one covers publications citation tactical analysis not of a large scale and is in line 
with a bibliometrics approach (Narin and Olivastro, 1994) that is used with the aim to measure impact of various scientific works in area of IMC and IC. Further research findings are introduced and Alberoni's (1984) ideas are linked up for better understanding, what does it means - to change value systems aiming to be the best and knowing how complex and slow those processes are in practical world, not speaking about theoretical basis. Thus, qualitative research is designed with the target to work with professionals hand in hand and during several phases of action research (Mills, 2000).

The chosen itinerary means the same as looking for the strategy for future effective communication and encouragement to implement the different thinking, which is more creative and coming into line with universal usage.

\section{Integrated Communication versus In- tegrated Marketing Communications}

Here is important to mention that IC is different than what is known as IMC. For example, Diane Gayeski (1998) explains: Integrated marketing communication establishes a model for co-ordinating marketing, advertising, and PR efforts, all of which are promotional and external in nature. What we are calling integrated communication is a model that encompasses both internal and external communication and its application for information dissemination, communication and collaboration, learning, and performance support. Integrated communication is the application of analysis, communication, and evaluation techniques to create and manage integrated, multifaceted interventions combining information, instruction, collaboration, business process design, feedback, and incentive systems to improve human performance in the workplace in order to achieve organisations' desired missions and visions.

It looks like the concept of IMC has become a starting point for recent and future debates (Spotts, Lambert, et al., 1998; Cornelissen and Lock, 2000). This phenomenon of integration in the field of organisation's communication and even of total organisation as was declared like the possibility successfully to compete and survive in the turbulent market of $21^{\text {st }}$ century (Schultz, 1997) has not been off a pre-paradigm stage. On the other hand, singes of globally adopted concept are supportive for those who define this new approach like not a one-day philosophy (Kitchen and Schultz, 1999). Issues of grey areas in the theory foundation of a new discipline are suggested to remove by rethinking the trend of dialogical communication as well as the notion of the whole complex understanding and the focus on harmoniously developed integrated approach adoption in the area of communication management effectiveness improvement (Armonienè, 2001).

What steps were made and what achievements we have during the first decade of IC phenomenon birth and existence? In general, public relations, marketing were meshed together with statistics, information science, economics, organisational behaviour (Pincus, 1999). Even more. The task of excellent co-ordination was related to elimination of barriers and not separation of training, which should be more flexible, organised as short time modules, and development as the permanent movement. The impressive amount of studies by Don E. Schultz supported findings about harmoniously developed IMC, which is a way not only to survive. It is the way to win in a very turbulent market, taking into consideration that new processes are not fast. Later studies of various scholars have the tendency to define and explain this new phenomenon like more general process; thus, the term of IC has been used more frequently.

Roles of marketing, advertising, human resources management and public relations specialists and their functions are also the field for debates, the same may be said about shifts in theoretical domains of mentioned disciplines. For example, Ben Wightman (1999) discussed the Grunigs and Thomas Hunter's suggestions mostly in the sphere of structural arrangements. It is some kind of signal about problems of deciding, what IC originally means and what higher level of importance it has. The real strength of the emerging concept is a variety of communication actions, equal voices for different communication forms and orchestration of them. Wightman's (1999) conclusion is related to the need of the great changes in organisational thinking and also the deficit of skilled IC professionals. His explanations about Clark Caywood's contribution to IC concept's renovation give support to Gayeski's works and also may form the united theoretical platform with Netherlands' scholars working in the same field.

Finally, the movement toward outside-in development (Schultz, 1997a) seems to be one of the greatest transformations and the mostly difficult to overcome obstacle. Possibility to prepare ourselves for managerial positions and to reach the mind of selected addressee is not so easy task, because of new developments and changes in the area of human communication. Quality of every communicative activity should not be replaced by quantity of information. Thus, understanding of the way stakeholder should drive realigning communications is not so simple process. Client 


\section{Integrated Communication}

or stakeholder sees and hears a flow of information from indistinguishable sources and the requirement is to get a response, to create two-way communication and to have communication generalists (Schultz, Tannenbaum and Stanley, 1994). Gayeski (1998) introduces the perfect expression of the possible basis for IC management model launching. Her "islands of communication" and the model of redesigned communications is strong support for the model of four stages of IMC development suggested by Don E. Shultz's (1997b). So, it seams that Gayeski's works and Schultz's practical suggestions may be the most important for creative adoption with the aim to move toward theoretical and methodological whole of the new phenomenon. Besides, scholars representing domains of advertising and public relations are introducing very interesting findings and the need to concentrate on IC as more developed and different stage of integrated approach implementation in the field of communication is in evidence.

Not so much surprisingly, that IC is the next and not opposite stage of evolutionary development of IMC.

\section{Towards the Research Design}

The main difficulties are related to the reality that IC has not been implemented or, how to say, almost no organisation can do this in a perfect or complete way - it is merely the set of perfect ideas for the $21^{\text {st }}$ century. So, how can we investigate and study something, what do not exists in reality? According to Karl E. Weick (1983), it is possible to do by the way of standards selection. The helpful method, which was used during the preparative stage of this research, was Delphi procedure (Lindstone and Turoff, 1975) implemented during spring 2000. The Delphi research, which produce high-quality information and is used to pick brains, measure opinion, was extremely useful for findings - research trends and problems prediction, the most important issues establishment - incorporation in the future qualitative research plans.

It is clear that research of integrated communication can not be based on a singular method or theory, it should be multi-disciplinary and multi-method and in line with Karl Erik Rosengren's ideas. He was the first, who said words about the cultivation of the "tulip rose": "Much as our hearts may ache for it, we shall never see the tulip rose. But roses and tulips may grow and blossom together, just as the individual researcher may alternate phases, of, say, participant and more stringent methods, and just as members of different schools and traditions may draw upon each other's work by means of entering into open and pro- ductive dialogue" $(1989,28)$. That is why scientific communication flows are chosen for quantitative measurement in this study.

Fortunately, there is no problem to combine methodologies in the study of the same phenomenon of integrated communication. Linda L. Putnam (1983) suggested a pluralistic approach to methodology when conducting interpretative research. So, interpretative approach, which is only one of several paradigms for studying organisational communication with the focus on the subjective, intersubjective, and socially constructed meanings of organisational actors, is chosen for this research. Additionally, works of Dianne Lewis are important as careful introduction of the technique of using several different methods, called triangulation and defined by Norman K.Denzin in 1978 (Lewis, 1995). Triangulation of data, investigator, theory, methodology are four types, which were firstly introduced by Denzin. Any kind of changes should be investigated by the way of compulsory using triangulation of theory and methodology. Data triangulation is a using as many different data sources as possible. This type has been also decided to use in the research process of integrated communication.

Another block of difficulties is related to the fact of IC scientific investigations geographical location mostly in the USA and absence of them in Lithuania. On the other hand, problems have been the basis of more creative and innovative research strategy preparing. The result was the virtual team (Devlin, 1999) concentration as especially beneficial decision.

In general, the preparatory stage included:

\section{Data triangulation:}

- Several methods of data collecting or triangulation were incorporated. Firstly, it was a review of academic literature related to the topic. Secondly, it was a review of professional literature related to communication and information management and recent trends of the practical activities in the field. Thirdly, it was a review of case studies.

- Delphi studies.

- Virtual team as a basis for action research preparation.

2. Theory and methodology triangulation:

- Type IV theories (Hawes, 1975) as a framework was chosen for a theoretical foundation. 
- Normative worldview was chosen as a basis for open-systems theory adoption.

- The version of the new institutionalism that is called rational choice approach combined with culture theory was suggested to apply (Armoniené, 2000).

- Interpretative approach was chosen for this research project of integrated communication.

- The start of qualitative and quantitative researches design.

\section{Qualitative methods}

Action research has been launched with a group of Lithuanian governmental institutions. Communication, information, international relations and media chief managers supported the research design in case of performance improvement and interest in the professional exchanges. All of them were very co-operative. 14 chief managers interviewed face-to-face expressed strong agreement as for main ideas of integrated approach. Here should be mentioned the fact that they were not educated as IC professionals. In spite of facts mentioned before, blocks of thematic items about:

- Communication activities co-ordination

- Producing a consistent message

- Possibilities to adopt some creative ideas from business sector

- Possibilities to plan strategically multi-channeled and outside-in communication and relationship systems

- Dynamic aspects of changes in the field of communication and information

were helpful for mutual understanding of the fact of practising IC in the initial stage.

Observation technique was also implemented. The main task was to get data about possibilities harmoniously develop values, which would strengthen movement toward integration and not disintegration of communication activities. The understanding how interviewed managers interpret their everyday activities and create future visions was the core of investigations.

\section{Implications}

Interviewed chief managers were experienced as communication/information/media/international relations'

professionals. Average experience in their careers $-8,8$ years. Results of examination of their values and opinions helped to form the main trends of possible future development:

- Fast implementation of new information and communication technologies will influence the need not to separate internal and external communications.

- IC, as an alternative to conservative traditions in the area of governmental communication system, will be successful only if it be supplemented by training and continuous education.

- Inconsistencies in messages will not be very problematic to overcome obstacle for governmental institutions.

- The need to communicate effectively with business sector and interest groups and also to prepare better public information and communication programs will strengthen the faster movement toward outside-in communication planning.

- Perfect access to not distributed information and opportunities to use databases, as a priority in many cases will lead to manipulative actions, which not support two-way communication.

Performed analysis of collected data provided evident finding about existing understanding that new value system launching and improvement as a slow process is of great importance to communication renovation. However, it is not always related to the requirement to change organisation's mission and vision at the same time or even long before structural, cultural, managerial preparations. Hence, it seams that the area of IC is broadening firstly because of internal interactivity and also external instability of organisational environment.

And last but not least implication: probability of successful implementation and maintaining of the drive toward IC for governmental sector in Lithuania is possible as a natural but not compulsory implemented process combined with permanent educational activities. Since new generation of communication professionals have not been trained according to in consecutive order rejected narrow specialisation and also mass communication traditions, people already working in the information and communication field should and may be empowered by the way of targeted learning activities launching.

\section{Quantitative/Bibliometrics methods}

The aim of bibliometrics methods using in this research is to evaluate the impact of cited papers made to the theoretical and methodological whole of IMC/IC formation. The 


\section{Integrated Communication}

initial attempt is to provide quantitative data for measuring the impact of scientific publications.

According to Henry Small (1999), a path through scientific papers might be required to follow citation or co-citation links. Thus, we should follow those links and try to identify the structure of an emerging research field. Citation analysis is based on the study of links among texts. Documented science communication flows are studied using indicators in documents. So, the cognitive content and not social aspects are investigated. The form of Cited text $\mathrm{X}$ Citing text analysis is targeted to study discursive relations (Leydesdorff and Amsterdamska, 1990). Studied relations among texts or linkage measurement are of tactical level (Narin and Olivastro, 1994).

The limit of this evaluation is that structure of an emerging research field is investigated not by examining the growth of publications in various journals. However, it would be reasonable to look at this phenomenon in a nascent state from such kind of knowledge export and penetration perspective in future studies.

Here should be mentioned that scientific studies on IMC are only in starting positions, most published articles are case or discussions presentations. The very beginning of concept formalization is related to Clark Caywood's and group of scholars from Northwestern University, USA, and their study presentation in 1991. Besides, few earlier works by Don E. Schultz, who represents mentioned group of scholars, have influenced some followers. The subject of IMC is generally accepted in the marketing literature (Kitchen and Schultz, 1999).

So, usage of citations as indicators is very limited because of not incorporation of co-citation analysis in this study. Simply, co-citation techniques are possible in not so early stages of concept development, when amount of scientific papers is not enough for producing co-citation maps. This emerging concept examination is based on bibliographic coupling methods with the aim to identify essential publications and sometimes predict future development trends. Bibliographic-coupling methods proceed from those citing papers, which share items in their reference lists (Glänzel, 2001).

A basis for citation analysis is data generated from Social Science Citation Index during March 2001. The search code $\mathrm{CW}=$ Cited Work has been used, timespan=All Years.

\section{Results and Findings}

Data presented (see Table 1) shows citation rates of publications by 12 researchers working in the emerging domain of IMC/IC. Only first author's names are used. Coauthored works by Schultz and Kitchen are calculated twice for each author.

Average citation rate per publication after correction for self and in-group citation is also incorporated. The share of self-citations in all citations as well as their share in all references reveals interesting aspects of an author's or a research group's role in the system of science communication. The great number of self-citations indicates a successful and dynamic publication activity since the author or group has then published numerous papers in refereed journals (Glänzel, 2001).

Co-authorship of Schultz and Kitchen $(1997,1999)$ and also the famous book by Schultz, Tannenbaum and Lauterborn as references for further self-citings are exclusively examples. Besides, we should take into consideration that the book by Schultz et al, 1992, 1993, 1994, has 20 citing references (CR): 8 CR in 1996, 6 CR - 1997, 4 CR - 1999, $1 \mathrm{CR}-2000,1 \mathrm{CR}-2001$. Such kind of statistical data helps to predict potentiality of mentioned scientific publications: it is an indication of possibility being integrated into the body of new emerging research domain (Braun, Glänzel and Schubert, 1985). It is evident fact that the strength of the topic was the highest in 1996, 1997, 1999, when average number of CR is 6. Decrease is in 2000.

So, having data about turn towards IC as a renewed concept starting from 1997, we can understand the possible changes in citation amounts and behaviour after a few years. Table 1 shows very clear differences between citation rates of authors working in the field from earlier time and those who published later. Surprisingly, works by Gayeski have not so much scientific communication links as was expected before this study. The only one CR is from the thematic field of educational activities. It may be explained by limitations of this study and using only one database. In case of this it may be very useful to incorporate studies of social organisation of scientific communication in future bibliometrics studies of this very dynamic scientific field development. Another unexpected finding was about J.E.Grunig's works rather week penetration in the field of IMC/IC: only 2 CR from the side of IMC/IC scholars during the time period 1992-2001. Publication by Wightman in 1999 is promising sign of future more close relations between representatives of neighbour- 
ing disciplines. Data related to Grunig's works is not mentioned in the table, but the fact is that the first decade of IMC/IC theoretical development was centred in Northwestern's University and decentralisation as well as closer relations with researchers from related subject areas has just started. On the other hand, results show evident impact and strength of publications by Caywood and also Duncan.

\begin{tabular}{|c|c|c|c|c|}
\hline & $\mathrm{NCA}$ & NCR & \multicolumn{2}{|c|}{ NCR/NCA NCR/NCA* } \\
\hline SCHULTZ DE & 39 & 146 & 3,74 & 2,08 \\
\hline KITCHEN PJ & 14 & 27 & 1,92 & 0,65 \\
\hline DUNCAN T & 6 & 20 & 3,33 & 3,17 \\
\hline STEWART DW & 4 & 6 & 1,50 & 1,25 \\
\hline CAYWOOD C & 3 & 7 & 2,33 & 2,33 \\
\hline GOULD SJ & 2 & 5 & 2,50 & 1,00 \\
\hline McARTHUR DN & 1 & 5 & 5,00 & 4,00 \\
\hline HUTTON JG & 1 & 4 & 4,00 & 4,00 \\
\hline RUST RT & 1 & 3 & 3,00 & 3,00 \\
\hline WIGHTMAN B & 1 & 2 & 2,00 & 2,00 \\
\hline LOW GS & 1 & 1 & 1,00 & 0,00 \\
\hline GAYESKI D & 1 & 1 & 1,00 & 1,00 \\
\hline \multicolumn{5}{|c|}{ Table 1. Citation Rates. } \\
\hline \multicolumn{5}{|c|}{$\begin{array}{l}\text { NOTE: NCA - NUMBER OF CITED REFERENCES, NCR - NUMBER OF } \\
\text { CITING REFERENCES, NCR/NCA - AVERAGE CITATION RATE PER } \\
\text { PUBLICATION, NCR/NCA* - AVERAGE CITATION RATE PER } \\
\text { PUBLICATION AFTER CORRECTION FOR SELF AND GROUP-CITATION } \\
\text { IS MADE. }\end{array}$} \\
\hline
\end{tabular}

The last finding may be supported by data presented as a result of bibliographic coupling method using (see Table 2). Publications by Duncan represent one of the mostly influencing items. Besides, all six of them have rather equal strength according to number of citing papers, which share items in their reference lists. It is very interesting result that shows the great impact of all publications created by one author. Data about influence of publications by Schultz and Kitchen is in line with data presented in Table 1 and confirms mentioned self-citation performance of very higher level. The fact about sharing items by scholars of the same domain shows absence of cross-disciplinary relations. The remarkable indication is data about the new- est publications in the field relational connections: Low, Gould with their shared references are on the list of bibliographical couples. Thus, citation flows or a path through scientific publications may help to indicate structure of scientific communication flows in this emerging research field. Publications by five authors (see Table 2) are linked with publications by Low, Gould, McArthur, Griffin and also Schultz and Kitchen mostly as self-citation result.

$\begin{array}{ll}\text { SCHULTZ DE } & 3 \mathrm{~B} 2,2 \mathrm{~B} 3,2 \mathrm{~B} 5,2 \mathrm{~B} 6,1 \mathrm{~B} 4 \\ \text { KITCHEN PJ } & 6 \mathrm{~B} 2,1 \mathrm{~B} 3 \\ \text { DUNCAN T } & 3 \mathrm{~B} 2,2 \mathrm{~B} 1,1 \mathrm{~B} 5 \\ \text { STEWART DW } & 1 \mathrm{~B} 3 \\ \text { CAYWOOD C } & 1 \mathrm{~B} 2\end{array}$

Table 2. Bibliographic coupling rates.

NOTE: Cited publications are not indicated because of conclusion decision about already mentioned the most influencing publications in the field.

B1: items are shared by Griffin, T. et al., 1998, and McArthur, D.N. and Griffin, T., 1997.

B2: items are shared by Kitchen, P.J. and Schultz, D.E., 1999, and Schultz, D.E. and Kitchen, P.J., 1997.

B3: items are shared by Kitchen, P.J. and Schultz, D.E., 1999, and Low, G.S., 2000

B4: items are shared by Low, G.S., 2000, and Gould, S.J. et al., 1999.

B5: items are shared by Gould, S.J. et al., 1999, and Kitchen, P.J. and Schultz, D.E., 1999.

B6: items are shared by Kitchen, P.J. and Schultz, D.E., 1999, and McArthur, D.N. and Griffin, T., 1997.

\section{Being in a Nascent State means Con- serving Energy}

The phenomenon of integrated communication has still been in pre-paradigm stage (Kitchen and Schultz, 1999; Schultz and Kitchen, 2000), which also may be named as a nascent state. Francesco Alberoni (1984) defines the nascent state (NS) as a tremendous energy. According to him, "all institutions and all value systems arose originally as a NS and often are only a way of channelling and conserving its tremendous energies" (83), he claims that the target of investigations is the perfect institution. Connecting-links may be indicated such as:

1. The emerging IC concept is en route with appearance of different value system. So, it is possible come to the conclusion that IC theory building is in a NS.

2. Organisations that are starting integration of communication may be defined as being in a NS. 


\section{Integrated Communication}

Finally, here may be summarised, that if the organisation in a NS starts to change it's communication management and eliminates external and internal barriers with the help of new technologies and implementation of integrated communication model, the amount of conserved energy may be very huge. Partly it is because of possibility to develop integration permanently and to start training of innovative kind. Strategic activities are also of the highest significance.

Alberoni's conclusion is that the probability is greatest for those people who are frustrated. What can be said about organisations? A few years before the most spread opinion was that large successful industrial companies adopt IMC/IC models more effectively. Surprisingly, it appeared that small companies are more likely to integrate their communications than large ones (Low, 2000). This finding supports idea about possible effectiveness of "frustrated" organisations or, being more exact, it is evident that small organisations are more flexible and with greater amount of vital power.

Rather similar finding about promising possibilities of small and middle enterprises was made during Delphi procedure completed in preparative phase of this study in spring 2000.

Organisation is a set of people having common aims or organised around an idea, sometimes around a leader. Thus, the highest level of management should adapt integration ideas firstly and understand the importance of communication success: the better communication of the organisation, the better possibilities to be alive in a new digital world.

\section{Conclusion}

This study is an attempt to bridge theory and practice. It seems that understanding of further development trends should support movement towards more universal models building. Theory formation of IC is very complex and also dynamic process and chosen presumption may be very helpful for future communication strategy creation. The individual conditions of every organisation should be the basis for creative and very careful outside-in communication planning.

Having results of quantitative research and understanding limitations of bibliometrics study that has been made, it would be reasonable to look at this phenomenon in a nas- cent state from more dynamic perspective in the further research.

\section{References}

Alberoni, F. (1984). Movement and institution. New York: Columbia University Press.

Armonienè A. (1999). New possibilities offered by information society: The perspective of governmental institution making maximum communication impact. Paper presented at international conference:"Information Society'99", Vilnius, 201-202.

Armonienè A. (2000). Integruotos komunikacijos teorinès prielaidos. (Translation: Theoretical premises of integrated communication). Informacijos mokslai, 13, 62-70.

Armonienè, A. (2001, In print). Integrated communication: A preparadigm stage. Klaipeda University:Tiltai.

Braun, T., Glänzel, W., and Schubert, A. (1985). Scientometric indicators: A 32 country comparative evaluation of publishing performance and citation impact. Singapore, Philadelphia: World Scientific.

Cornelissen, J.P. and Lock, A.R. Theoretical concept or management fashion? Examining the significance of IMC. Journal of Advertising Research, 40 (5), 7-15.

Devlin, K. (1999). Infosense: Turning information into knowledge. New York: W.H. Freeman and Company.

Duncan, T. \& Everett, S. E. Client perceptions of integrated marketing communications (1993). Journal of advertising research, 33(3), 30-39.

Gayeski, D. \& Woodward, B. (1996). Integrated Communication: From Theory toPerformance. Paper presented at the Research Foundation of the International Association of Business Communicators, winner of "Top Paper" award. Accessed December 21, 1999 at ttp://www.omnicomassociates.com

Gayeski, D.M. (1998). Integrative communication: A blueprint for restructuring the management of information dissemination, collaboration, and learning in organisations. Published in International Communication Focus. England: London. (Note: the text was forwarded by D.Gayeski for author of this study personally in an electronical form).

Gorman, G.E. and Clayton, P. (1997). Qualitative research for the information professional: A practical handbook. London: Library Association Publishing.

Glänzel, W. (2001). Introduction into theory and application of bibliometric indicators. Paper presented at Nordic PhD course in bibliometrics. Hundested, Denmark.

Gould, S.J., Lerman, D.B., and Grein, A.P. (1999). Agency perceptions and practices on global IMC. Journal of Advertising Research, 39(1), 7-20. 
Andžela Armonienè

Hawes, L.C. (1975). Pragmatics of analoguing: Theory and model construction in communication. Reading, MA: Addison-Welsey.

Kitchen, P.J. and Schultz, D.E. (1999). A multy-country comparison of the drive for IMC. Journal of Advertising Research, 39(1), 21-38.

Lewis, D. (1995). Research strategic change - Methodologies, methods and techniques. In: Hussey, D.E. (ed.). Rethinking strategic management: Ways to improve competitive performance, 269-316. Chichester, New York: John Wiley \& Sons.

Leydesdorff, L. and Amsterdamska, O. (1990). Dimension of citation analysis. Science, Technology and Human Values, 15(3), 305-335.

Low, G.S. (2000). Correlates of integrated marketing communications. Journal of Advertising Research, 40(3), 27-39.

Lundstone, H. and Turoff, H. (1975). The Delphi Method. MA: Addison - Wesley.

Marshall, C. and Rossman, G.B. (1999). Designing qualitative research. $3^{\text {rd }}$ ed. Thousand Oaks, London, New Delhi: SAGE.

Mills, G.E. (2000). Action research. Upper Saddle River: NJ: Prentice Hall.

Narin, F. and Olivastro D. (1994). Bibliometrics/theory, practice and problems. Evaluation Review,18(1), 65-76.

Nemec, R. (1999). From communication 101 to communication 2001: What's new? Everything. Communication World. Accessed February 2, 2000 at

nttp://www.1abc.com/cw/backiss/1999cw/augsept/nemec.htm

Pincus, D.J. (1999). Everything's changed... A retrospective on the evolving field of communication. Communication World 2 16(8), 16-21.

Putnam, L.L. and Pacanowsky, M.E. (1983). Communication and organizations: An interpretive approach. Beverly Hills, London, New Deli: SAGE Publications.

Rosengren, K.E. (1989). Paradigms lost and regained. In: B.Dervin, et al. (Eds.), Paradigm dialogues: Theories and issues, 21-39. Everly Hills, CA: SAGE.
Schultz, Don E., Tannenbaum, S.I., Lauterborn, R.F. (1994). Integrated marketing communications. $2^{\text {nd }}$ ed. Lincolnwood: NTC Business Books.

Schultz, D.E. (1997). Integration is critical for success in $21^{\text {st }}$ century. Marketing News, 31(19), 26-27.

Schultz, D.E. (1997a). Organize IMC programs from the outside-in. Marketing News, 31(22), 6.

Schultz, D.E. (1997b). Check out your level of integration. Marketing News, 31(17), 17-26.

Schultz, D.E., \& Kitchen, P. J. (1997). Integrated marketing communications in U.S. advertising agencies: An Exploratory study. Journal of Advertising Research, 37(5), 7-18.

Schultz, D.E., \& Kitchen, P. J. (2000). A response to "theoretical concept or management fashion?". Journal of Advertising Research, 40(5), 17-21.

Small, H. (1999). A passage through science: Crossing disciplinary boundaries. Library trends, 48(1). 72-108.

Spotts, H.E.; Lambert, D.R.; et al. (1998). Marketing deja vu: The discovery of integrated marketing communications. Journal of Marketing Education, 20(3), 210-218.

Yin, R.K. (1994). Case study research: Design and methods. $2^{\text {nd }}$ ed. The USA: SAGE Publications, Inc.

Weick, K.E. (1983). Organisational communication: Toward a research agenda. In: Putnam, L.L. and Pacanowsky, M.E. Communication and organisations: An interpretative approach, 13-31. Beverly Hills, London, and New Deli: SAGE Publications.

Wightman, B. (1999). Integrated communications: Organisation and education. Public Relations Quartely, 44 (2), 18-22.

\section{Biography}

Andžela Armonienè is a PhD student enrolled in the doctoral programme of the Faculty of Communication at the University of Vilnius, Lithuania. Her field of interest and research project is related to integrated communication. 